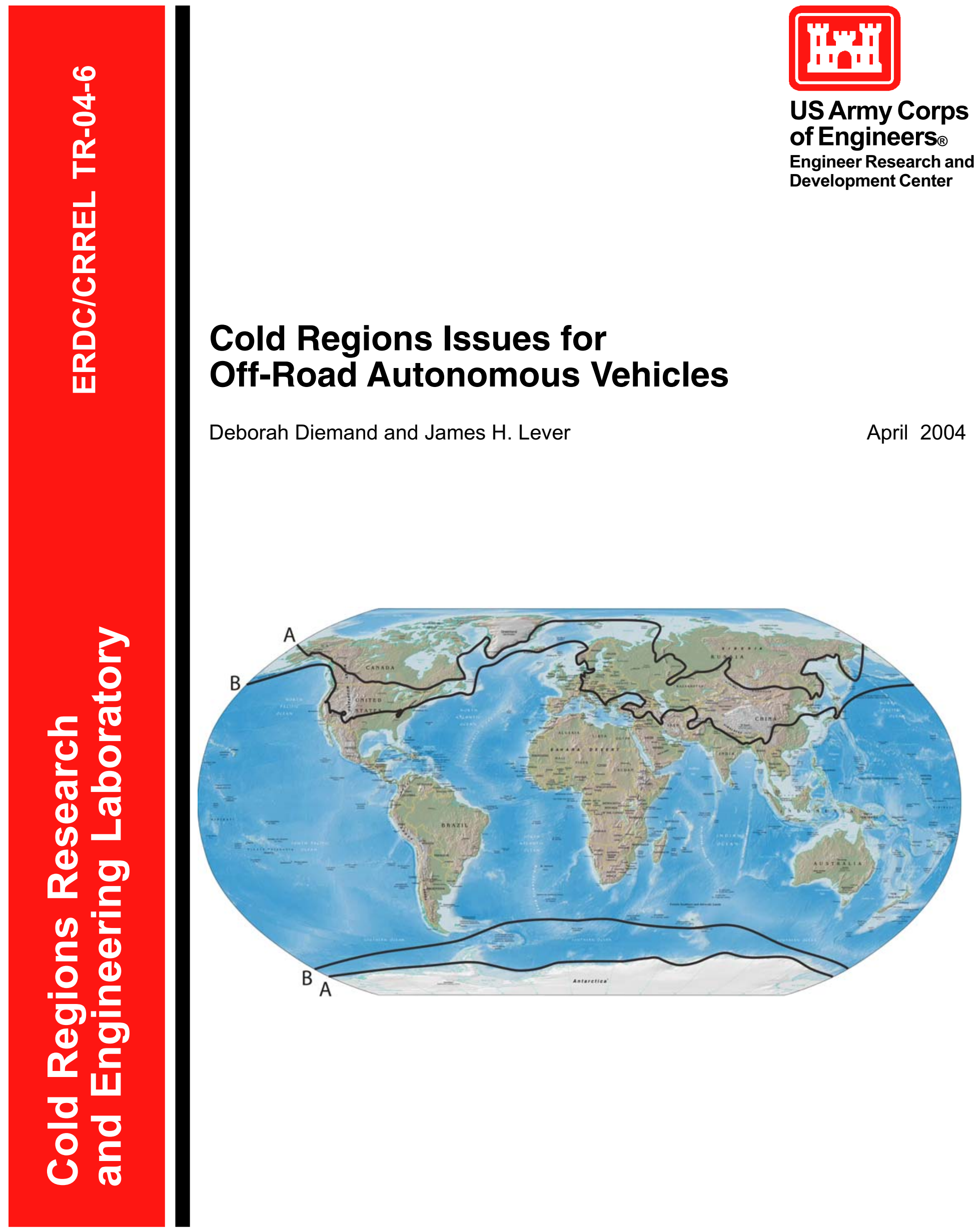


Front cover: Regions of the world considered severely cold (A) and moderately cold (B). Lines are based on Bates and Bilello (1966). World map from DI Cartography Center (1999). 


\section{Cold Regions Issues for Off-Road Autonomous Vehicles}

Deborah Diemand and James H. Lever

Approved for public release; distribution is unlimited.

Prepared for U.S. ARMY CORPS OF ENGINEERS 


\begin{abstract}
About half of Earth's land mass experiences mean temperatures below $0^{\circ} \mathrm{C}$ during the coldest month. Attendant conditions pose major challenges to the operation of off-road autonomous vehicles. Low-temperature effects on lubricants, materials, and batteries can impair a robot's ability to operate at all. Cold starting will be a serious problem if missions require long periods of engine shutdown. Deep snow can easily immobilize vehicles on terrain that would otherwise pose no problems. Blowing snow and icing can also degrade the performance of sensors needed for navigation and target detection. Winter operation of passenger vehicles and construction equipment provides guidance to surmount cold-regions effects on robotic vehicles. This report identifies problems likely to be encountered, simple preventative measures, and references for additional information. Conditions are sufficiently demanding that off-road autonomous vehicles must be designed for and tested in cold regions if they are expected to operate there successfully.
\end{abstract}

DISCLAIMER: The contents of this report are not to be used for advertising, publication, or promotional purposes. Citation of trade names does not constitute an official endorsement or approval of the use of such commercial products. All product names and trademarks cited are the property of their respective owners. The findings of this report are not to be construed as an official Department of the Army position unless so designated by other authorized documents. 


\section{CONTENTS}

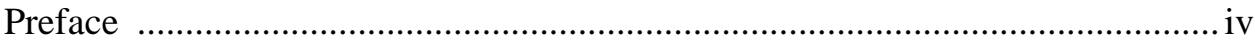

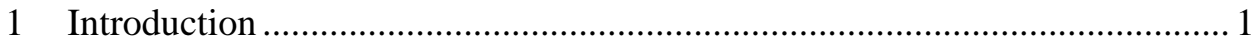

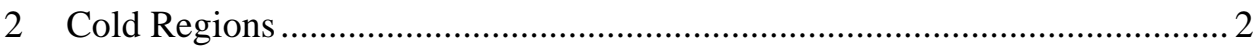

3 Equipment Operability Problems in Cold Regions ....................................... 6

Temperature-Dependent problems ............................................................. 6

Other Weather Conditions Affecting Operability ........................................ 13

4 Autonomous Mobility Issues in Cold Regions............................................ 14

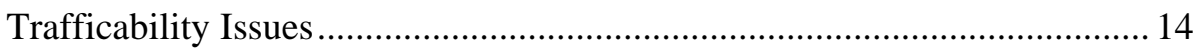

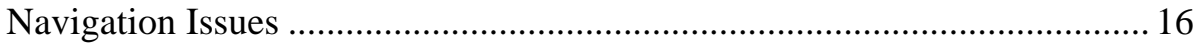

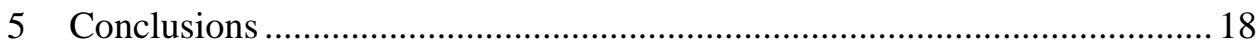

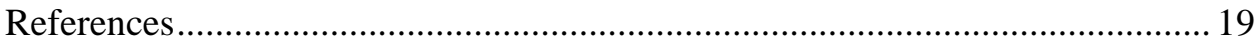

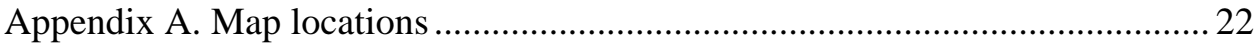

Appendix B. Detailed temperature data.......................................................... 24

\section{ILLUSTRATIONS}

Figure 1. Regions of the world considered severely cold and moderately cold .. 2

Figure 2. Areas of Eurasia where average mean monthly temperature is less

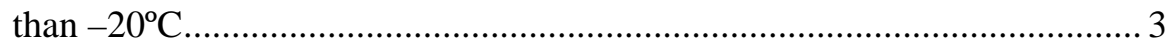

Figure 3. Areas of Eurasia where average minimum monthly temperature is less

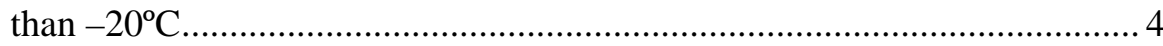

Figure 4. Plots of the January mean daily temperatures from Curapca and Khanty-Mansiysk, as well as the average daily maxima and minima and historical extremes for each day 


\section{PREFACE}

This report was prepared by Deborah Diemand, Physical Scientist, and Dr. James H. Lever, Mechanical Engineer, Applied and Military Research Branch, U.S. Army Engineer Research and Development Center (ERDC), Cold Regions Research and Engineering Laboratory (CRREL), Hanover, New Hampshire.

Funding for this work was provided by the Defense Advanced Research Projects Agency (DARPA) Unmanned Ground Combat Vehicle Program, and ERDC work package Ground Platform and Terrain Mechanics Modeling Support, work unit Mobility of Lightweight and Robotic Vehicles.

The authors acknowledge Dr. Scott Fish (DARPA) and Dr. Sally Shoop (CRREL) for supporting this work. The authors also thank Jane Mason for preparing the cold regions map, and Drs. Shoop and Phetteplace for their helpful reviews of the manuscript.

The Commander of the Engineer Research and Development Center is Colonel James R. Rowan, EN. The Director is Dr. James R. Houston. 


\title{
Cold Regions Issues for Off-Road Autonomous Vehicles
}

\author{
DEBORAH DIEMAND AND JAMES H. LEVER
}

\section{INTRODUCTION}

This report briefly describes cold-regions issues of concern for off-road autonomous vehicles (i.e., robots). It identifies the most serious problems likely to be encountered, simple preventative measures, and references for additional information.

Essentially, the difficulties of maintaining and operating manned vehicles in cold regions are exacerbated for unmanned vehicles. Operability issues such as cold starting may be serious if missions require long periods of engine shutdown for stealth or energy conservation. Vehicles can easily become immobilized in deep snow covering terrain that would otherwise pose no problems. Blowing snow and icing can also degrade the performance of sensors needed for autonomous navigation and target/intruder detection.

Experience with winter operation of automobiles, trucks, and construction equipment provides a wealth of guidance to avoid many problems. However, many issues unique to off-road autonomous mobility, navigation, and control are compounded by winter conditions and will require considerable effort to surmount. Conditions are sufficiently demanding that ground robots must be designed for and tested in cold regions if they are expected to operate there successfully. 


\section{COLD REGIONS}

About one-quarter of Earth's land mass (all of Siberia, Greenland, and Antarctica; most of Canada and Alaska; and parts of China and northern Europe) may be termed "severely cold" (Bates and Billello 1966, Freitag and McFadden 1997). Mean annual air temperatures are below $0^{\circ} \mathrm{C}$, maximum snow depths exceed $60 \mathrm{~cm}$, and lakes and rivers are ice covered for more than 180 days. Another one-quarter (including most of the United States and Eurasia) may be termed "moderately cold," where mean air temperatures during the coldest month are below $0^{\circ} \mathrm{C}$. Figure 1 shows the extent of cold regions so defined. While these definitions are useful, vehicles respond to actual conditions. It is important to note that daily minimum temperatures can be $20^{\circ} \mathrm{C}$ lower than monthly means, and snowdrifts can be several times deeper than the average snow cover.

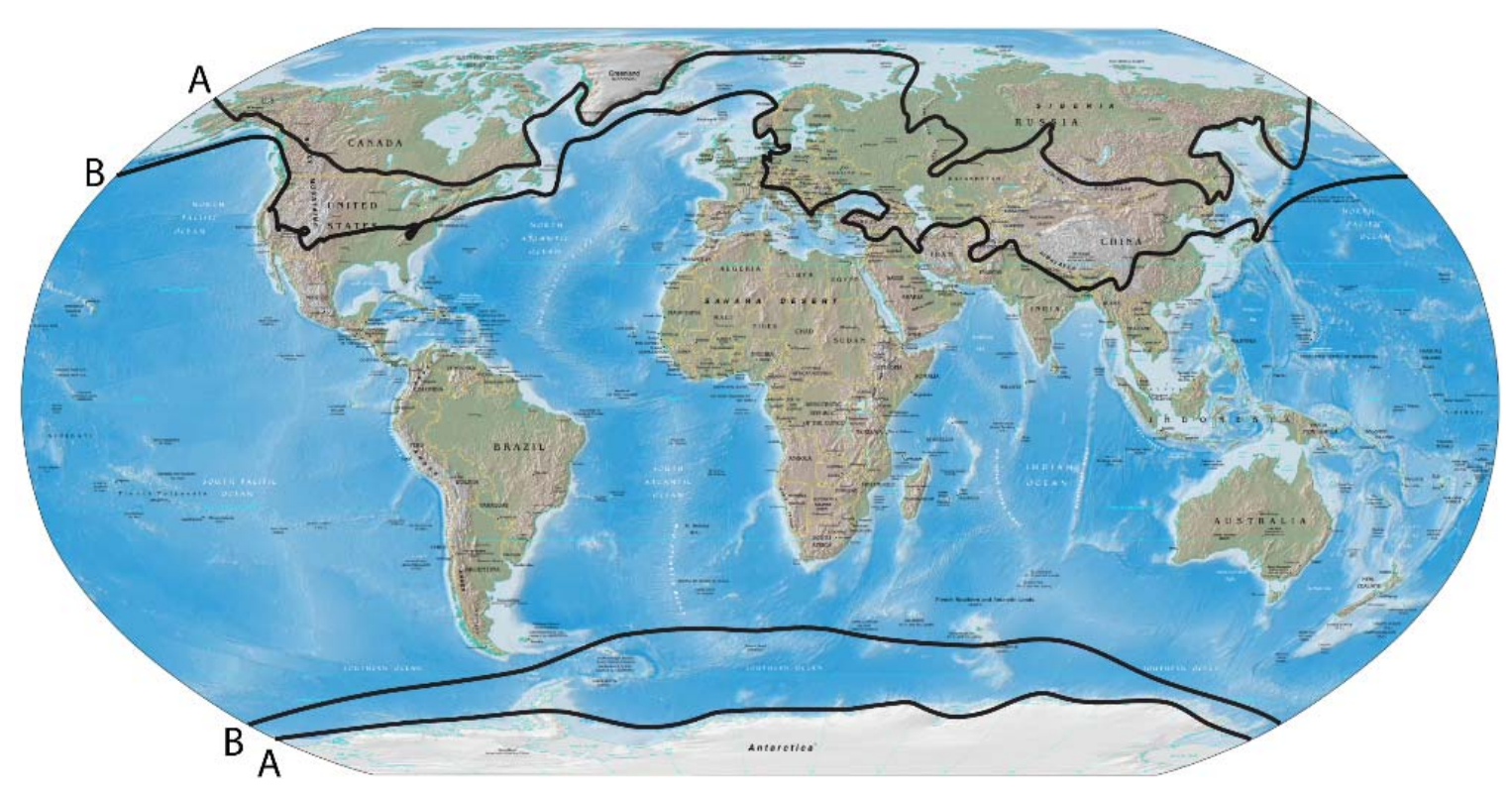

Figure 1. Regions of the world considered severely cold $(A)$ and moderately cold (B). Lines are based on Bates and Bilello (1966). World map from DI Cartography Center (1999).

There are few areas in the world where extremely low temperatures are commonplace. Not surprisingly, these areas are not heavily populated. Sustained temperatures below $-40^{\circ} \mathrm{C}$ are commonly present during winter months in the polar regions, on the Greenland ice cap, at extremely high elevations, in central Alaska, parts of northern Canada, and north central Asia. However, vehicles 
begin to experience problems whenever temperatures drop below freezing; below $-20^{\circ} \mathrm{C}$ problems with lubricants, batteries, and materials can be significant. Also, regardless of temperature, the presence of snow cover, ice, frozen or thawing ground, or freezing precipitation frequently creates problems for vehicle travel.

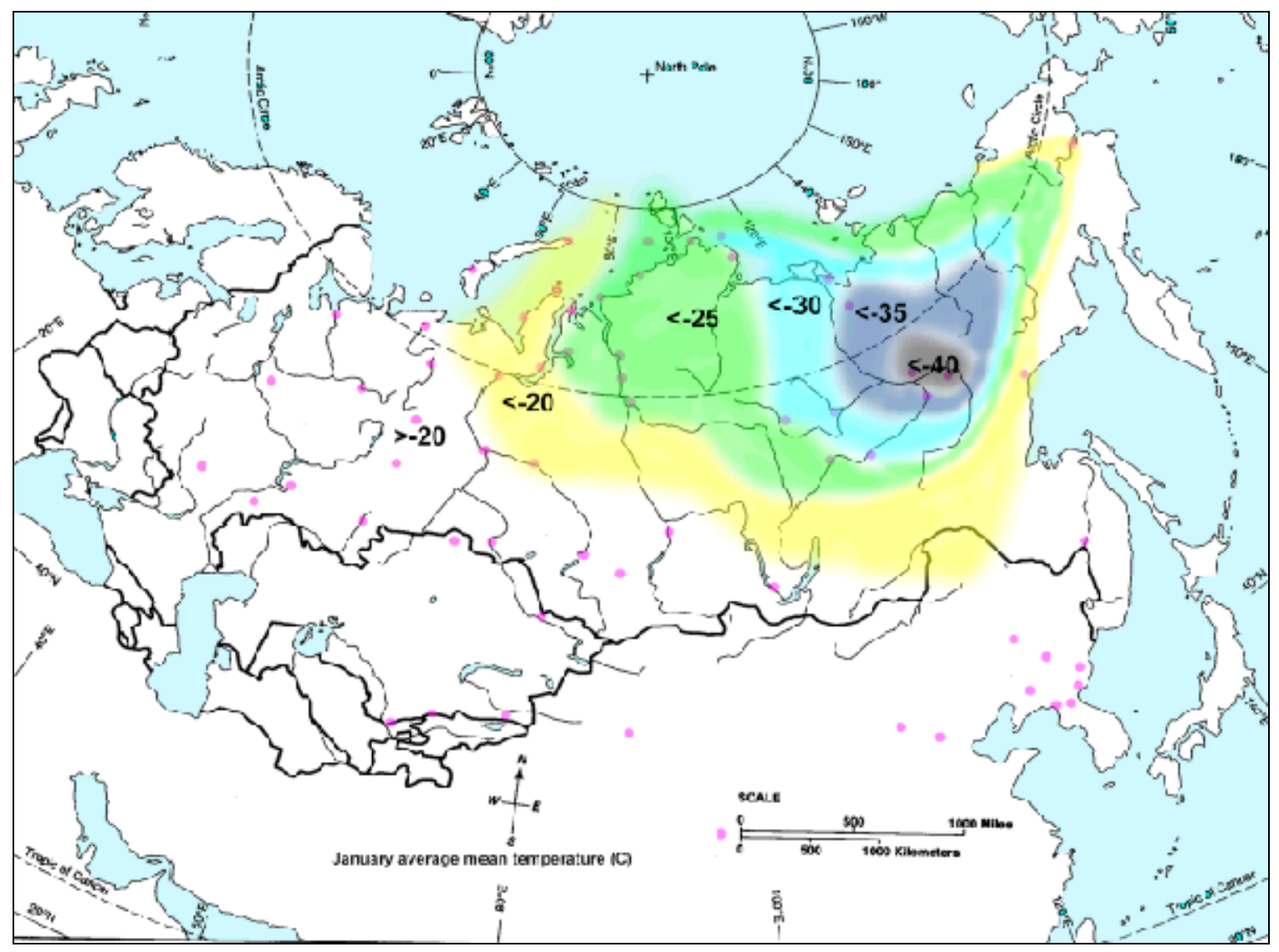

Figure 2. Areas of Eurasia where average mean monthly temperature is less than $-20^{\circ} \mathrm{C}$.

An example will serve to illustrate how climatic data may be used to define vehicle design temperatures for a region of interest. Figure 2 is a map of Eurasia showing average mean monthly temperatures for the month of January, which in most northern locations is the coldest month. Figure 3 shows the average daily minimum temperatures for the same time and region. The data used to construct these temperature distributions are from the National Climate Data Center (1996) and are listed in Appendix A. A more detailed data set for two sites is given in Appendix B. Curapca, Russia, is located in the coldest core shown on the maps, with an average mean daily temperature in January of less than $-40^{\circ} \mathrm{C}$. 
Khanty-Mansiysk, Russia, is located at the western edge of the highlighted region, with an average mean daily temperature greater than $-20^{\circ} \mathrm{C}$. The two are roughly $1^{\circ}$ of latitude apart and $140 \mathrm{~m}$ of elevation. This suggests that latitude and elevation alone are not useful guides for estimating temperatures that may be encountered.

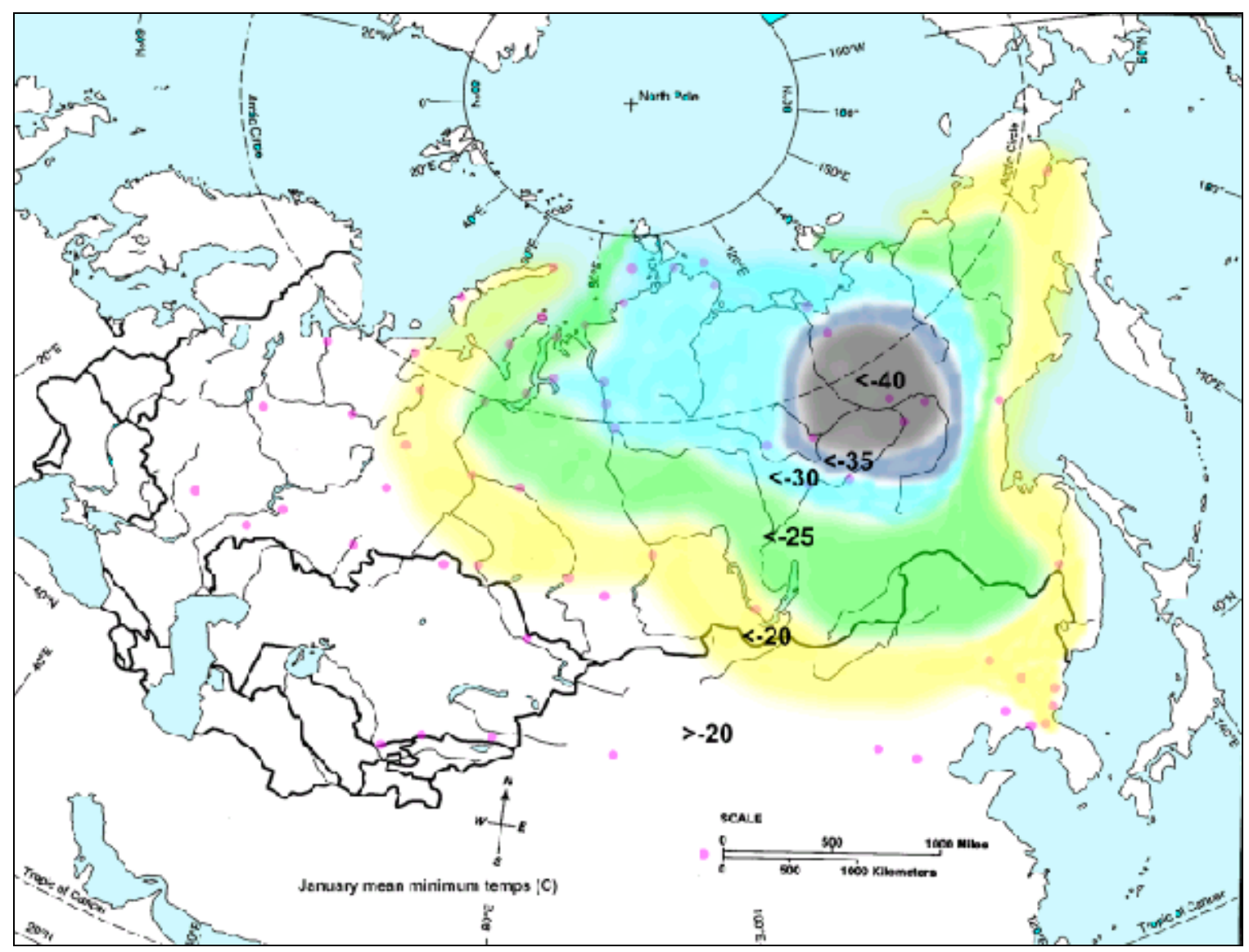

Figure 3. Areas of Eurasia where average minimum monthly temperature is less than $-20^{\circ} \mathrm{C}$.

In addition to monthly averages, the temperature extremes possible for an individual site are important. Figure 4 shows plots of the January daily average mean temperatures (bold line) for Curapca and Khanty-Mansiysk. The mean curve is bracketed by the daily average maximum and minimum temperatures (dark grey) and these are bracketed by the historical extremes (light grey). It is clear from these plots that while the mean January temperatures appear to be quite steady, possible excursions for the averages may prove catastrophic in 
terms of vehicle operability. Standard deviations for January tell the same story (Appendix A). For example, Khanty-Mansiysk has a monthly average minimum temperature of $-23^{\circ} \mathrm{C}$ with a standard deviation of about $10^{\circ} \mathrm{C}$, so that temperatures below $-30^{\circ} \mathrm{C}$ are common in January. Because daily minimum temperatures often occur overnight, vehicles in nighttime silent mode (engine off) may experience cold soaking that impedes start-up and smooth operation the next morning.
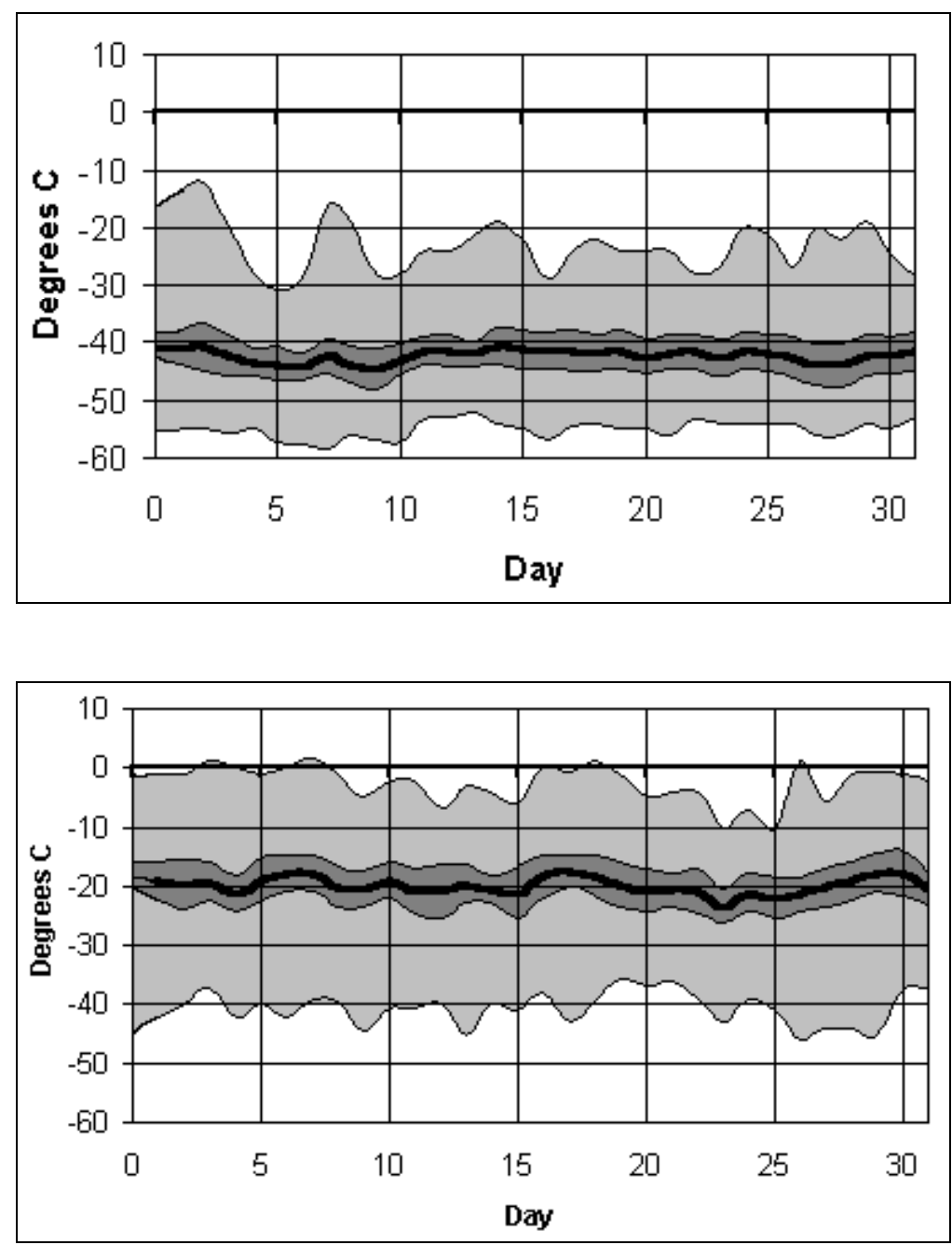

Figure 4. Plots of the January mean daily temperatures from Curapca (top) and Khanty-Mansiysk (bottom) as well as the average daily maxima and minima (dark grey) and historical extremes (light grey) for each day. 


\section{EQUIPMENT OPERABILITY PROBLEMS IN COLD REGIONS}

Included here are brief descriptions of the nature of, and solutions for, problems commonly encountered in operating vehicles and construction equipment in cold regions. Robotic vehicles will encounter similar problems but may be expected to perform well without human intervention. Note that the coverage here is certainly not exhaustive. Diemand (1990; 1991a, b, c, d; 1992) and Freitag and McFadden (1997) provide much more detail and extensive references.

\section{Temperature-Dependent Problems}

\section{Engine Oil}

Lubricants represent the single most critical problem encountered by vehicles in cold regions (Diemand 1990). Engine oils must work effectively at extremes defined by ambient low temperatures and full-load high temperatures. Coldstarting problems and poor lubrication result if engine oil is too viscous at low temperatures. Prolonged idling at low temperatures can also cause excessive sludge formation from blow-by products, including water, gasses, and unburned fuel.

Oil performance may be characterized by several measures, including viscosity at temperature extremes (say, $-30^{\circ} \mathrm{C}$ and $100^{\circ} \mathrm{C}$ ), viscosity index (a high value indicates the oil is insensitive to temperature variations), and borderline pumpability temperature (a measure of the ability of the oil to circulate at low temperatures).

Several good quality, multigrade oils are available for use in cold regions, including Oil, Engine, Arctic (OEA), a 0W20 synthetic lubricant used by the military for ambient temperatures from $40^{\circ} \mathrm{C}$ to $-50^{\circ} \mathrm{C}$. In addition, all machinery in cold regions is equipped with engine heaters, and both block and pan heaters are highly recommended to minimize cold-starting problems (Diemand 1990). Frequent oil and filter changes are also recommended.

\section{Other Lubricants}

In general, the drivetrain will need to perform under the most extreme conditions, since it is continuously exposed to ambient temperatures. Again, the lubricant must have sufficient viscosity to protect the gears from high contact stresses at operating temperatures, yet flow well at low ambient temperatures to 
permit start-up. Multigrade 75W90 synthetic gear oil is commonly used in cold regions (Diemand 1990). Even low-temperature lubricants will thicken at sufficiently low temperatures and, especially at start-up, abrupt accelerations may cause breakage or damage to gears and axles. Slow, gentle acceleration and operation is recommended until the drivetrain warms to operating temperature.

Arctic hydraulic and brake fluids are also available and advisable for lowtemperature use (Diemand 1990). Water absorption, leakage, excessive pump water, and stiffening are the main concerns. Even with a suitable fluid, it is best to warm hydraulic systems at no load before subjecting them to full-load application.

Fuel

The heavier grades of diesel fuel are seldom used in cold regions because they tend to solidify at relatively high temperatures. For example, the cloud point of DL-2, the temperature at which the heavier components begin to crystallize, is about $-12^{\circ} \mathrm{C}$. That of $\mathrm{JP}-8$, on the other hand, is lower than $-60^{\circ} \mathrm{C}$, making it a better choice for use in the extreme cold. However, even light fuels will ignite with greater difficulty as the temperature falls, and heating the fuel tank (or at least the fuel lines) should be considered.

\section{Coolant}

With a proper coolant/water ratio, the coolant will not freeze above about $-40^{\circ} \mathrm{C}$. In fact, even below this it will not damage the engine since it will freeze into a slurry rather than a solid block and will therefore not cause expansion damage as water would. However, if the engine is forced to start when the coolant is not fully fluid, the coolant will not circulate properly and engine damage could result from local overheating.

\section{Low Temperature Operation}

While low temperatures make starting an engine very difficult, they also may have an adverse affect on operation, and heat retention measures should be used. The optimum design of heat retention devices should enable the engine to reach an operating temperature range of $85-93^{\circ} \mathrm{C}$ under the worst possible conditions. In extremely cold temperatures an engine that has not been properly winterized may not reach this temperature, resulting in greatly increased numbers of failures and reduced fuel efficiency.

A few of the problems experienced by engines run at low operating temperatures are as follows: 
- Oil dilution from unburnt fuel

- Sludge deposits in the crankcase

- Carbon deposits on the valves

- Reduced injector performance

- Excessive vibration and torsional loads.

While these, and other problems, are greatly increased when the engine is allowed to idle for long periods, they will still be present during normal operation.

Windchill is a very important factor in maintaining sufficiently high temperature for normal operation of both the engine and other components. While wind speed has no affect on the actual measured air temperature, it has a very strong affect on the rate of heat loss. Heat loss always increases with wind speed, but the proportional increase is most significant at low wind speeds. That is, an increase in wind speed from 0 to $5 \mathrm{~m} / \mathrm{sec}$ results in far greater increase in heat loss than that from 10 to $15 \mathrm{~m} / \mathrm{sec}$.

There are several important implications of windchill. First, when the engine is shut down, it will cool to ambient temperature much faster in windy than in calm conditions, and cold-starting procedures will more likely be necessary to restart it. Second, parts of the machine that are more exposed to environmental conditions, such as the drive elements or transmission, may warm very little, if at all, and will cool down faster at shutdown. Third, components that require heating to operate smoothly (e.g., payload mechanisms) will require greater heating power to maintain the necessary operating temperatures.

High heat loss can create problems similar to those created by starting up equipment too abruptly after it has been cold soaked. Even if the engine itself is sufficiently warm for normal operation, remote parts of the machine that are still very cold can be damaged by placing too great a load on them too soon. Stiffened lubricants, including hydraulic fluids, can place abnormally high loads on joints and linkages. Seals can break. Structural elements can bend or crack. Drivetrain elements can snap. It is crucially important to initiate operation slowly in very cold temperatures, and to continue slower-than-normal operation if the initial stiffness does not fully abate.

Thermal analysis of the vehicle (e.g., Shoop et al. 1997) can be useful for determining transient and steady state temperatures of critical systems and the benefits possible from insulation and selective heating of components. 
Metals

High-strength steels generally become brittle as temperature drops, making them susceptible to fracture (Diemand 1991d, Freitag and McFadden 1997). Welds, sharp corners, cracks, or holes can act as stress concentrators. Shock or vibrations loads can also be more severe in the cold as rubber isolation mounts stiffen with decreasing temperature. These effects combine to increase the likelihood of fracture failures, especially for highly stressed components or rapid loading rates.

It is good practice to choose steels with brittle transition temperatures lower than expected minimum air temperatures and to design critical components using fracture mechanics. Most aluminum and stainless-steel alloys do not become brittle with decreasing temperature but usually have lower strengths. Thus lowtemperature structural design can involve trading ultimate strength for better fracture behavior.

Tin can also pose problems at low temperatures (Diemand 1991d). High-tin plain bearings and solder (> 35\% tin) should be avoided. Zinc galvanizing on wire rope can also become brittle and crack below $-20^{\circ} \mathrm{C}$.

\section{Elastomers}

Elastomers (natural and synthetic rubbers) become increasingly brittle as temperature decreases, and failures often occur before the material has warmed to operating temperature. Failure of rubber timing belts can be disastrous. Manufacturers for common products (e.g., fan belts, timing belts, and seals) will usually specify their safe low-temperature limits. As a rule of thumb, choose silicone products whenever possible. These maintain their flexibility at both temperature extremes, but, in general, lack strength. They are the seal of choice at low temperatures.

Fan belts are the most common casualties among elastomers. Besides installing one specified for the temperatures expected, it is good practice to ensure that any vehicle heading into expected low temperatures is equipped with a nearly new belt, that is, one that has been used for a few days at moderate temperatures.

Rubber shock mounts will also stiffen at low temperature. Use silicone rubber if possible or allow the mount to warm up (if it can do so) before subjecting the system to heavy vibration (e.g., high-speed driving).

Tires can develop temporary flat spots on vehicles left overnight at low temperatures. Stiffening of the tire can also make it susceptible to damage if 
driven too fast over angular objects, such as stumps or stones. The vehicle should be driven slowly until the tires have warmed up. Stiffening of the rubber also increases the rolling resistance of tires driven at ambient low temperatures (Shoop et al. 1997).

\section{Plastics}

Many plastics become very brittle at low temperatures and are susceptible to cracking by thermal stresses. It is hard to specify which are good and which are less so, since there are so many variables among the feed stocks, plasticizers, manufacturing methods, applications, and so forth. However, it is not a good idea to use a plastic component in any situation where it is likely to be exposed to significant vibration or sharp blows at temperatures below $-20^{\circ} \mathrm{C}$.

\section{Differential Contraction}

At temperatures below $-20^{\circ} \mathrm{C}$, material differential-contraction problems become important, especially if steel shafts penetrate aluminum housings or collars with a small tolerance. During operation, this problem may not be apparent, since frictional heat will keep both parts sufficiently warm. However, if the vehicle is left to cold soak in a sufficiently cold location, the parts may bind. Similar problems may develop between metals and plastics, depending on their contraction rates and the ambient temperature.

\section{Inflation Pressure}

Maintaining proper tire pressure can also be difficult. At low temperature, tubeless tires may not maintain an airtight seal. Consequently, use of inner tubes is common in cold regions, even in tubeless tires (Diemand 1990d).

Also, inflation pressure will decrease if the tire is initially inflated in warm conditions $\left(\mathrm{T}_{1}, \mathrm{P}_{1}\right)$ according to the ideal gas law, $\mathrm{P}_{1} / \mathrm{P}_{2}=\mathrm{T}_{1} / \mathrm{T}_{2}$, where the temperatures are in degrees Kelvin $\left({ }^{\circ} \mathrm{C}+273\right)$. For example, $120 \mathrm{kPa}(17 \mathrm{psi})$ is the required inflation pressure at $20^{\circ} \mathrm{C}$ to achieve a tire pressure of $100 \mathrm{kPa}(14 \mathrm{psi})$ at $-30^{\circ} \mathrm{C}$. Although the pressure reduction is small, it can be important to ensure a good seal for tubeless tires and proper high-speed behavior of the tires. Inflation in ambient conditions eliminates this problem. Central tire inflation systems (CTIS) would also ensure proper inflation pressure provided air leaks at low temperatures are not significant. 


\section{Batteries}

Lead-acid batteries become vulnerable to freezing when discharged, do not charge well when cold, and lose power at low temperatures. But they are inexpensive and have been used extensively in automotive and construction equipment in cold regions. Good practice is to warm up lead-acid batteries before cold starting the engine or charging the batteries.

Nickel-cadmium (NiCd) batteries perform better than lead-acid ones at low temperatures (Diemand 1991c, Eveready Battery 2001a). They are unlikely to freeze and have better cranking power and charge acceptance for the same temperature. They are, however, more expensive.

Nickel-metal hydride (NiMH) batteries have higher energy density than NiCd batteries. However, they lose more capacity at low temperatures than NiCd and lead-acid batteries, and below $0^{\circ} \mathrm{C}$ charging is not advisable (Eveready Battery 2001b). Both NiCd and NiMH batteries must be charged at reduced rates below $15^{\circ} \mathrm{C}$.

Lithium-ion batteries experience relatively little capacity loss at low temperatures and can be charged at normal rates above $0^{\circ} \mathrm{C}$ (Gave et al. 2001, SAFT 2001, Ultralife Batteries 2002). Charging at reduced rates can occur as low as $-30^{\circ} \mathrm{C}$ (Gave et al. 2001). Although Li-ion batteries are more expensive than $\mathrm{NiCd}$ and NiMH, they can be the battery of choice for hybrid-electric drive systems where their higher energy density offsets their higher cost. Superior cold-weather performance is then an added benefit.

One solution to poor low-temperature battery problems might be to use a thermoelectric generator powered by an alternate fuel source, such as propane, which could trickle-charge the batteries of choice at the same time it is warming the batteries, engine, electronics, or any other critical system. Another approach is to insulate the battery case and use waste heat from other components to keep the batteries warm. For all-electric operation (e.g., silent movement), it may be appropriate to warm the batteries before applying significant power demands. Current delivery will then warm the batteries if they are well insulated. Thermal analysis of the battery pack (e.g., Shoop et al. 1997) can help optimize its design and operation.

\section{Electronics}

Individual electronic components are generally susceptible to failure at high temperatures and usually perform better as ambient temperatures decrease. However, reliability problems do occur when electronics are exposed to belowfreezing temperatures. 
Temperature cycling can cause moisture condensation and increase the risk of shorts if care is not taken to seal the electronic compartments. This can occur at large scale when a cold vehicle is brought indoors.

Wire insulation becomes brittle with decreasing temperature, making it prone to failure if flexing is required. Wire and cable insulation should be selected to ensure flexibility at the lowest ambient temperatures expected.

The increased brittleness of solder and differential contraction of circuit boards at low temperature can also cause failures of electronic components, especially if they are subject to shock or vibration. Troubleshooting these intricate systems in the cold is particularly hard on personnel, so work is often performed in heated enclosures. Unfortunately, cracked connections can work properly when the component is warmed up, making troubleshooting more difficult than usual. Fault diagnosis in the cold is preferable, even if it simply involves swapping subsystems until the fault is isolated. Again, care must be taken when bringing cold electronic components indoors to avoid condensation problems.

\section{Start-up}

Cold starting may be the most difficult problem for an unmanned vehicle in very cold conditions. First, cranking the cold engine will make heavy demands on the batteries, because of stiffened lubricants, at a time when they are least able to deliver. Second, the unheated fuel may be slow to ignite, requiring an extended period of cranking. Starting aids such as glow plugs improve fuel volatility but increase battery drain. Third, this is the time when problems caused by ice in the sumps, pumps, blowers, and other mechanisms will appear.

Assuming that the engine starts without difficulty, actually moving the vehicle is the next problem. As mentioned above, any abrupt movements in the drivetrain or steering before the fluids have had a chance to warm slightly could result in crippling damage to the vehicle.

It would be wise to consider the energy trade-off to preheat batteries, fuel, and lubricants versus the extra effort required to cold start the engine. Selectively insulating key components could help minimize the energy required to preheat them. Also, use of a thermoelectric generator should be considered to preheat as many systems as possible as well as supplying electricity to any key components. 


\section{Other Weather Conditions Affecting Operability}

Low temperatures alone do not delineate all regimes of concern for vehicle operability. Conditions of frozen or freezing precipitation pose their own set of problems.

\section{Blowing Snow Infiltration}

In cold regions, the snow particles are reduced to very small size as they are moved by the wind. Like water, blowing snow can and will work its way into any compartment that is not completely sealed (e.g., engine compartments, air intakes and exhausts, and payload bays). Selective sealing or heating of critical components helps, but in extreme cases the entire vehicle must be heated to melt the packed snow before mechanisms will operate safely. In either case, the meltwater from infiltrated snow must be allowed to drain away safely without interfering with electronic gear or freezing in drain holes or moving parts.

Wet Snow, Freezing Rain, and Frost

Blowing snow, especially at temperatures near its melting point, will plaster itself on all upwind surfaces. Any lenses, ports, intakes, or external mechanisms that cannot tolerate this sort of obstruction will need to be provided with some means to prevent it (e.g., heaters or covers). Similarly, freezing-rain and frost accumulations will have to be prevented or devices provided for their removal. Freezing shut of seals around ports or mechanisms can also occur when temperatures drop after rainfalls, with adhesive bond strengths sufficient to require special design provisions ( $>1 \mathrm{MPa}$ ). Similar problems can occur after fording if ambient temperatures drop below freezing. Heating of critical components may be appropriate. Also, low-adhesion materials and coatings can be used to reduce bond strengths and improve shedding of ice (CRREL 2003). 


\section{AUTONOMOUS MOBILITY ISSUES IN COLD REGIONS}

Off-road autonomous mobility presents daunting problems under the best of conditions, and winter conditions amplify trafficability, navigation, and control concerns. Interestingly, exceptions also exist. Frozen saturated ground and lakeice cover, if sufficiently deep and bare of snow, increase trafficability compared with their unfrozen counterparts. Similarly, low-ground-pressure vehicles can travel easily over deep snow without needing to negotiate the underlying obstacles. Robots may be able to perform better than manned vehicles if they are equipped with systems for automatic traction and braking control. However, sensing the terrain conditions ahead poses major problems during winter conditions.

\section{Trafficability Issues}

Trafficability is the ability of a terrain to support vehicle mobility. It can be characterized by measures such as shear strength or cone index and compared with vehicle requirements to predict Go/No-Go conditions or maximum speeds over possible routes.

\section{Snow Cover}

Deep snow drastically reduces vehicle mobility due to increased compaction resistance, dragging of undercarriage parts, and reduced traction. On packedsnow and icy surfaces, loss of traction for acceleration, steering, and braking is the main concern. A significant literature exists to predict these effects for conventional vehicles (Wong 1989, Blaisdell et al. 1990, Richmond et al. 1990, 1993, 1995), yet the problems manifest themselves every winter.

Autonomous off-road mobility in snow-covered terrain presents a difficult challenge. In general, knowledge of snow depth and strength is necessary to predict vehicle Go/No-Go conditions and consequently to avoid becoming stuck in deep snow (Wong 1989). Vehicles that can travel efficiently over deep, soft snow are invariably tracked vehicles with ground pressures less than about $7 \mathrm{kPa}$ (1 psi) (Mellor 1963). Modern snowmobiles fit into this category. Small robots will require even lower ground pressures to compensate for their smaller ground clearances (Lever 2002). Wheeled vehicles with low ground pressures can travel successfully over snow depths less than the vehicles' ground clearance and less than the radius of the wheels (Richmond et al. 1995). 
Assuming it can move through or over the snow, higher rolling resistance due to snow compaction must also be accounted for in the vehicle's energy budget and mission plan. Rolling resistance exceeding $5 \%$ of vehicle weight is common for travel through shallow snow (Richmond et al. 1995). Resistance can exceed $10 \%$ of vehicle weight for travel over deep snow (Lever 2002).

Interaction of snow and obstacles is of particular concern and essentially unknown. For example, it might be very difficult for an unmanned vehicle to extract itself from a deadfall or ditch obscured by soft, deep snow. Conversely, hard-packed drifted snow and thin ice crusts can support low-ground-pressure vehicles and thus obliterate obstacles. Obtaining information about the state of the snowpack over a terrain thus becomes an important requirement. It may be appropriate to design some small robots for good over-snow mobility (tracked vehicles with low ground pressure and large ground clearance relative to vehicle size). These robots would travel well over snow-covered obstacles and survey the terrain for larger robots with more limited over-snow mobility.

Rapid temporal variations during snowstorms pose unique problems. A vehicle on easily traveled frozen soil might find itself buried in a snowdrift a few hours later. Because trafficability and visibility can both decrease rapidly during snowstorms, an unmanned vehicle could become immobile by attempting to move or simply by staying put. What would constitute fail-safe behavior for the vehicle? Perhaps the robot should execute small intermittent movements to avoid inundation while waiting out the storm. Thawing conditions or rain-onsnow events can similarly abruptly reduce the trafficability of hard-pack snow covers. Forecast and planning for such events must be part of robot operations in winter conditions.

\section{Frozen and Thawed Soils}

The conditions of frozen and thawed soils represent opposite extremes in terms of vehicle mobility. When frozen, weak wet soil is usually trafficable if the frost depth is sufficient to support the vehicle's weight. However, as frozen soil begins to thaw, the underlying frost hinders soil drainage, increasing motion resistance and decreasing traction. Richmond et al. (1995) provide empirically based guidance to predict vehicle mobility for these cases. Again, obtaining knowledge of the depth of frost and the depth of an overlying thawed layer becomes a key requirement for predicting autonomous vehicle mobility. Because thaw depth can change diurnally, this information must be available to the vehicle in near-real-time. 


\section{Floating Ice Covers}

Ice covers over freshwater lakes and slowly flowing rivers are used routinely to support vehicle traffic. Guidance exists regarding the minimum ice thickness needed to support a given vehicle for a variety of conditions (U.S. Army 2002). Vehicles should move slower than the critical speed of the ice sheet (where wave effects become important). For $0.3 \mathrm{~m}$ of ice over deep water, this speed is about $7.5 \mathrm{~m} / \mathrm{s}(27 \mathrm{~km} / \mathrm{h})$ and increases with ice thickness. The minimum thickness, h, of good, solid ice to support a slowly moving vehicle of weight $\mathrm{P}$ is $\mathrm{h}(\mathrm{m}) \sim 0.03 \mathrm{P}^{1 / 2}$ $(\mathrm{kN})$. To park a vehicle on a floating ice cover for several hours, the minimum ice thickness should be about twice this value. Corrections exist for travel over sea ice (U.S. Army 2002). Ice covers on fast-flowing sections of rivers are generally rougher, less stable, and not recommended for vehicle travel. Also, when air temperatures have been above freezing for more than 24 hours, all ice covers can be unsafe.

Floating ice covers offer robotic vehicles, especially lightweight ones, mobility advantages compared with circumventing unfrozen lakes and rivers. However, some estimate of ice thickness is needed, from local measurements or air-temperature records, to indicate that ice thickness in the area exceeds minimum values.

\section{Avalanches}

In snowy mountainous regions, avalanches pose serious risks to unmanned (and manned) vehicles. General guidance is available to predict high-risk areas and times, but local knowledge of avalanche "chutes" and threatening snow/ weather conditions is invaluable. When necessary to stop for extended periods, locations should be chosen that minimize the risk of avalanches. In locations subject to avalanche activity, the noise of vehicle start-up or shear stress from vehicle passage could be enough to trigger an avalanche.

\section{Navigation Issues}

Off-road autonomous vehicles will require information about the local terrain to navigate successfully through it. This includes data on the state of the ground, snow depth and strength, location and size of obstacles, etc. Onboard sensors must be able to "see" through the atmosphere and interpret the resulting images. Winter conditions affect both the transmission of sensor signals and the background clutter of the scene. 


\section{Falling or Blowing Snow}

During a snow event, especially accompanied by wind, visibility will be greatly reduced, as well as the effectiveness of any lights used. Obstacles such as holes, ditches, rocks, and deadfalls will be obscured. This will also be true whenever a pre-existing snow cover can be scoured loose by wind and blown along the surface (wind speeds $>10 \mathrm{~m} / \mathrm{s}$ ). The depth of this blowing-snow layer depends on a number of factors but can easily be as high as a vehicle. Depending on the sensors used, "visibility" can effectively reduce to zero. Sensor degradation during periods of falling or blowing snow will reduce autonomous navigation capability independent of mobility concerns.

Ice Fog

Ice fog occurs as moisture in the air freezes directly to ice crystals at temperatures about $-40^{\circ} \mathrm{C}$. It can create a serious visibility problem. Ice fog can occur naturally in maritime areas or places with open water such as lakes, rivers, sewage lagoons, or hot springs. It can also be produced at warmer temperatures by vehicle exhaust, especially at start-up. This self-produced fog can obscure vision systems and be a signature-control issue for stealth operations. Solutions include exhaust diffusers or condensers (Diemand 1992).

\section{Fog over Snow}

Fog formed when a warm air layer lies over snow can be particularly dense and consequently severely degrade the performance of infrared and visible imaging systems.

\section{Heterogeneous Ground Conditions}

Heterogeneous wet and frozen ground conditions can cause highly variable background reflections (clutter) for radar and passive microwave sensors. This may affect the system's ability to recognize obstacles, trees, and other terrain features of interest. 


\section{CONCLUSIONS}

Despite ample experience with manned vehicles, addressing cold-regions issues affecting off-road autonomous vehicles will require considerable effort. It begins with good design practice to anticipate potential operability, mobility, and navigation problems. Measurement and forecast of weather conditions, terrain trafficability, and sensor visibility are also essential for ground vehicles to operate unattended in cold regions. Clearly problems that lead to inoperability (e.g., failure to cold start) or immobility (e.g., getting stuck in deep snow) warrant greatest attention.

In some regards, robots might fare better than manned vehicles because they will likely include systems for health monitoring (e.g., engine temperatures, battery state-of-charge) and mobility monitoring (e.g., traction, wheel slip, sinkage) that can be programmed for cold-regions conditions. Nevertheless, design for and testing in these conditions will be essential to achieve good performance. The large extent of cold regions and the desire to operate unmanned vehicles in them justifies this effort.

Naturally, vehicles will perform better in cold regions if they are specifically designed for the conditions expected. Retrofitting existing vehicles with winter packages is commonly done and can reduce many problems. Unfortunately, some problems, such as mobility over deep snow, require solutions that govern the vehicle configuration. We recommend that some fraction of the robots expected to operate in cold regions be designed specifically to perform well in them. These vehicles could then chart safe routes and serve as scouts for the remaining robots to follow. They could also be deployed as sentries when other robots would be immobile or inoperable. 


\section{REFERENCES}

Bates, R.E., and M.A. Bilello (1966) Defining the cold regions of the Northern Hemisphere. U.S. Army Cold Regions Research and Engineering Laboratory, Hanover, New Hampshire, Technical Report 178.

Blaisdell, G.L., P.W. Richmond, S.A. Shoop, C.E. Green, and R.G. Alger (1990) Wheels and tracks in snow: Validation of the CRREL shallow snow mobility model. U.S. Army Cold Regions Research and Engineering Laboratory, Hanover, New Hampshire, CRREL Report 90-9.

CRREL (2003) Ice adhesion values for materials and coatings. U.S. Army Engineer Research and Development Center, Cold Regions Research and Engineering Laboratory, Hanover, New Hampshire. (http://www.crrel.usace.army.mil/welcome/facilities/Ice_Adhesion_Lab.html)

DI Cartography Center (1999) Physical map of the world, August 1999, 802657AZ (R00349) 8-99.

Diemand, D. (1990) Lubricants at low temperatures. U.S. Army Cold Regions Research and Engineering Laboratory, Hanover, New Hampshire, Cold Regions Technical Digest 90-1.

Diemand, D. (1991a) Automotive fuels at low temperatures. U.S. Army Cold Regions Research and Engineering Laboratory, Hanover, New Hampshire, Cold Regions Technical Digest 91-2.

Diemand, D. (1991b) Automotive and construction equipment for Arctic use: Heating and cold starting. U.S. Army Cold Regions Research and Engineering Laboratory, Hanover, New Hampshire, Cold Regions Technical Digest 91-3.

Diemand, D. (1991c) Automotive batteries at low temperatures. U.S. Army Cold Regions Research and Engineering Laboratory, Hanover, New Hampshire, Cold Regions Technical Digest 91-4.

Diemand, D. (1991d) Automotive and construction equipment for Arctic use: Materials problems. U.S. Army Cold Regions Research and Engineering Laboratory, Hanover, New Hampshire, Cold Regions Technical Digest 91-5.

Diemand, D. (1992) Winterization and winter operation of automotive and construction equipment. U.S. Army Cold Regions Research and Engineering Laboratory, Hanover, New Hampshire, Cold Regions Technical Digest 92-1.

Eveready Battery (2001a) Battery application manual: Nickel-cadmium. (http://data.energizer.com) 
Eveready Battery (2001b) Battery application manual: Nickel-metal hydride. (http://data.energizer.com)

Freitag, D.R., and T. McFadden (1997) Introduction to Cold Regions Engineering. New York: ASCE Press.

Gave, G., Y. Borthomieu, B. Lagattu, and J.P. Planchat (2001) Evaluation of a low temperature Li-ion cell for space. In Proceedings, 52nd International Astronautical Congress, Toulouse, France, paper IAF-01-R.2.08. Published by American Institute of Aeronautics and Astronautics.

Lever, J.H. (2002) Scaling deep-snow mobility for lightweight robotic vehicles. 14th International Conference of the Society for Terrain-Vehicle Systems, Vicksburg, Mississippi. Available on CD-ROM from ISTVS, U.S. Army Cold Regions Research and Engineering Laboratory, Hanover, New Hampshire.

Mellor, M. (1963) Oversnow transport. U.S. Army Cold Regions Research and Engineering Laboratory, Hanover, New Hampshire, CRREL Monograph III-A4.

National Climate Data Center (1996). International Station Meteorological Climate Summary. Version 4.0 September 1996. CD jointly produced by Fleet Numerical Meteorology and Oceanography Detachment, National Climate Data Center, and USAFETAC OL-A.

Richmond, P.W., G.L. Blaisdell, and C.E. Green (1990) Wheels and tracks in snow: Second validation study of CRREL shallow snow mobility model. U.S. Army Cold Regions Research and Engineering Laboratory, Hanover, New Hampshire, CRREL Report 90-13.

Richmond, P.W. (1993) A discussion of deep snow mobility models. Presented at NATO Reference Mobility Model (NRMM) Technical Management Committee Meeting, Trier, Germany, 12-13 May 1993.

Richmond, P.W., S.A. Shoop, and G.L. Blaisdell (1995) Cold regions mobility models. U.S. Army Cold Regions Research and Engineering Laboratory, Hanover, New Hampshire, CRREL Report 95-1.

SAFT (2001) Medium prismatic lithium-ion batteries. (http://www.saftbatteries.com/)

Shoop, S.A., P.W. Richmond, and D. Diemand (1997) Electric vehicle performance in northern climates. In Proceedings, 14th International Electric Vehicle Symposium, Orlando, Florida, 11-17 December 1997.

Ultralife Batteries (2002) Technical data: LWC-L Li-ion rechargeable battery. (http://www.ultralifebatteries.com/rechargeable-products.asp) 
U.S. Army (2002) Ice engineering. U.S. Army Corps of Engineers, Engineering Manual No. 1110-2-1612, Chapter 8, Washington, D.C.

(http://www.usace.army.mil/inet/usace-docs/eng-manuals/em1110-21612/toc.htm)

Wong, J.Y. (1989) Terramechanics and Off-road Vehicles. Amsterdam: Elsevier Science Publishers. 


\section{APPENDIX A. STATION LOCATIONS AND AVERAGE TEMPERATURES (National Climate Data Center 1996)}

\begin{tabular}{|c|c|c|c|c|c|c|c|}
\hline \multirow[b]{2}{*}{ City name } & \multicolumn{2}{|c|}{ Location } & \multirow{2}{*}{$\begin{array}{c}\text { Elevation } \\
(\mathrm{m})\end{array}$} & \multicolumn{4}{|c|}{ Month of January averages } \\
\hline & Latitude & Longitude & & Mean $\left({ }^{\circ} \mathrm{C}\right)$ & St. Dev. & Min. $\left({ }^{\circ} \mathrm{C}\right)$ & St. Dev. \\
\hline Xining & $3637 N$ & $10146 \mathrm{E}$ & 2263 & -6.0 & & -12.7 & \\
\hline Anju & $3937 \mathrm{~N}$ & $12539 \mathrm{E}$ & 41 & -7.5 & 4.8 & -12.2 & 5.6 \\
\hline Beijing & $3956 \mathrm{~N}$ & 116 17E & 55 & -3.3 & 2.9 & -8.2 & 2.9 \\
\hline Changjin & $4022 \mathrm{~N}$ & $12715 \mathrm{E}$ & 1081 & -15.3 & 4.9 & -22.6 & 6.4 \\
\hline Pungsan & $4029 N$ & 128 09E & 1206 & -14.7 & 4.7 & -21.3 & 5.3 \\
\hline Hohhot & $4049 N$ & $11141 \mathrm{E}$ & 1065 & -11.0 & 3.4 & -16.5 & 3.6 \\
\hline Tashkent & $4116 \mathrm{~N}$ & 069 16E & 489 & 1.5 & & -2.1 & \\
\hline Benxi & $4119 N$ & 123 47E & 185 & -12.8 & 5.7 & -18.2 & 6.6 \\
\hline Hyesan & $4124 \mathrm{~N}$ & $12810 \mathrm{E}$ & 714 & -15.7 & 4.4 & -22.5 & 5.2 \\
\hline Chunggang & $4147 \mathrm{~N}$ & $12653 \mathrm{E}$ & 332 & -15.6 & 4.8 & -22.1 & 5.7 \\
\hline Samjiyon & $4149 N$ & $12819 \mathrm{E}$ & 1386 & -17.2 & 5.3 & -22.4 & 6.0 \\
\hline Dzhambul & $4251 \mathrm{~N}$ & $07123 E$ & 653 & -3.2 & 6.6 & -7.5 & 6.8 \\
\hline Alma Ata & $4314 N$ & 076 56E & 847 & -4.8 & 5.2 & -8.9 & 5.3 \\
\hline Urumqi & $4347 \mathrm{~N}$ & $08737 \mathrm{E}$ & 919 & -11.9 & & -15.8 & \\
\hline Harbin & $4545 N$ & $12646 \mathrm{E}$ & 143 & -18.3 & 4.8 & -24.0 & 5.2 \\
\hline Qiqihar & $4723 N$ & $12355 E$ & 148 & -18.4 & 4.1 & -24.0 & 4.3 \\
\hline Ersov & $5120 \mathrm{~N}$ & 048 21E & 106 & -10.7 & 6.6 & -14.0 & 7.5 \\
\hline Balasov & $5133 N$ & 043 09E & 154 & -9.1 & 6.6 & -12.2 & 7.6 \\
\hline Irkutsk & $5216 \mathrm{~N}$ & $10421 E$ & 513 & -19.4 & 5.9 & -24.8 & 6.7 \\
\hline Kuybyshev/Bezencuk & $5315 N$ & 050 27E & 44 & -12.1 & 7.3 & -15.9 & 8.5 \\
\hline Magnitogorsk & $5321 N$ & $05905 E$ & 382 & -15.0 & 6.3 & -18.8 & 7.1 \\
\hline Novokuznetsk & $5344 N$ & $08711 \mathrm{E}$ & 308 & -14.8 & 7.0 & -18.5 & 7.7 \\
\hline Petropavlovsk & $5450 N$ & 069 09E & 136 & -16.0 & 7.2 & -19.8 & 7.9 \\
\hline Omsk & $5456 \mathrm{~N}$ & 073 24E & 123 & -16.5 & 7.2 & -20.4 & 7.8 \\
\hline Novosibirsk & $5502 N$ & $08454 \mathrm{E}$ & 177 & -15.8 & 7.2 & -19.3 & 8.0 \\
\hline Krasnoyarsk & $5600 N$ & 092 53E & 277 & -16.3 & 8.7 & -20.7 & 9.4 \\
\hline Sverdlovsk & $5648 N$ & 060 38E & 237 & -14.2 & 7.4 & -17.8 & 8.3 \\
\hline Buj & $5829 N$ & $04132 \mathrm{E}$ & 97 & -11.9 & 8.8 & -15.4 & 10.1 \\
\hline Okhotsk & $5922 \mathrm{~N}$ & $14312 \mathrm{E}$ & 6 & -20.7 & & -23.3 & \\
\hline Olekminsk & $6024 N$ & $12025 \mathrm{E}$ & 226 & -31.1 & 8.9 & -34.8 & 8.7 \\
\hline Aleksandrovskoye & $6026 \mathrm{~N}$ & $07752 \mathrm{E}$ & 47 & -20.6 & 9.4 & -24.7 & 9.9 \\
\hline Lensk & $6043 N$ & $11453 \mathrm{E}$ & 243 & -29.0 & 9.6 & -33.2 & 9.8 \\
\hline Khanty-Mansiysk & $6058 \mathrm{~N}$ & 069 04E & 40 & -19.4 & 8.9 & -23.2 & 9.5 \\
\hline
\end{tabular}




\begin{tabular}{|c|c|c|c|c|c|c|c|}
\hline \multirow[b]{2}{*}{ City name } & \multicolumn{2}{|c|}{ Location } & \multirow{2}{*}{$\begin{array}{c}\text { Elevation } \\
(\mathrm{m})\end{array}$} & \multicolumn{4}{|c|}{ Month of January averages } \\
\hline & Latitude & Longitude & & Mean $\left({ }^{\circ} \mathrm{C}\right)$ & St. Dev. & Min. $\left({ }^{\circ} \mathrm{C}\right)$ & St. Dev. \\
\hline Syktyvkar & $6140 N$ & $05051 \mathrm{E}$ & 119 & -15.4 & 9.1 & -19.0 & 10.0 \\
\hline Amderma & $6141 \mathrm{~N}$ & 061 41E & 53 & -19.2 & 8.1 & -22.8 & 8.1 \\
\hline Curapca & $6202 N$ & $13236 \mathrm{E}$ & 179 & -41.5 & & -45.3 & \\
\hline Yakutsk & $6205 N$ & 129 45E & 103 & -39.9 & & -43.7 & \\
\hline Chernyshevskiy & $6232 \mathrm{~N}$ & 111 14E & 424 & -31.2 & 8.1 & -34.3 & 7.9 \\
\hline Nyurba & $6317 N$ & $11820 \mathrm{E}$ & 129 & -35.7 & 9.0 & -40.1 & 8.7 \\
\hline Batamay & $6331 N$ & 129 26E & 79 & -41.5 & 6.2 & -45.7 & 6.1 \\
\hline Arkhangel'sk & $6435 N$ & $04030 \mathrm{E}$ & 13 & -13.8 & 9.2 & -17.4 & 10.2 \\
\hline Anadyr & $6447 N$ & $17734 \mathrm{E}$ & 62 & -20.6 & & -24.1 & \\
\hline Pechora & $6507 N$ & 057 06E & 56 & -19.3 & 10.8 & -23.3 & 11.6 \\
\hline Turuhansk & $6547 \mathrm{~N}$ & 087 57E & 32 & -25.9 & 9.9 & -30.0 & 10.4 \\
\hline Salekhard & $6632 N$ & $06632 \mathrm{E}$ & 16 & -23.8 & 9.1 & -28.1 & 9.1 \\
\hline Igarka & $6728 N$ & 086 34E & 30 & -26.7 & 10.1 & -30.3 & 10.4 \\
\hline Nar' Jan-Marq & $6739 N$ & $05301 E$ & 7 & -17.7 & 9.7 & -21.7 & 10.5 \\
\hline Novy Port & $6741 \mathrm{~N}$ & 072 52E & 12 & -24.4 & 8.7 & -28.5 & 8.4 \\
\hline Antipayuta & $6909 N$ & 077 OOE & 4 & -26.8 & 9.0 & -31.0 & 8.9 \\
\hline Dudinka & $6924 \mathrm{~N}$ & $08610 \mathrm{E}$ & 19 & -27.1 & 9.3 & -31.0 & 9.6 \\
\hline Sakhandzha & $6945 N$ & $12812 \mathrm{E}$ & 315 & -36.7 & 7.7 & -40.6 & 7.4 \\
\hline Cape Kharasavey & $7124 \mathrm{~N}$ & 067 38E & 18 & -22.8 & 9.2 & -26.8 & 9.1 \\
\hline Tiksi & $7135 \mathrm{~N}$ & $12855 \mathrm{E}$ & 8 & -30.7 & 6.4 & -33.8 & 6.5 \\
\hline Mongatalyang & $7159 N$ & 075 24E & 21 & -24.3 & 8.7 & -28.0 & 8.6 \\
\hline Malyie Karmakuly & $7223 N$ & 052 44E & 16 & -14.9 & 7.3 & -18.0 & 7.7 \\
\hline Belyy Island & $7320 \mathrm{~N}$ & 070 02E & 6 & -24.1 & 8.2 & -28.3 & 8.1 \\
\hline Dickson Island & $7330 N$ & 080 24E & 47 & -25.2 & 7.1 & -28.5 & 7.0 \\
\hline Cape Sterlegova & $7524 N$ & 088 47E & 10 & -28.1 & 7.4 & -31.6 & 7.2 \\
\hline B. Pronchishchevoy & $7532 N$ & $11331 \mathrm{E}$ & 6 & -29.2 & 6.7 & -32.5 & 6.3 \\
\hline Andreya Island & $7648 \mathrm{~N}$ & $11050 \mathrm{E}$ & 6 & -30.7 & 7.6 & -34.3 & 7.3 \\
\hline Cape Zehlaniya & $7657 \mathrm{~N}$ & 068 35E & 8 & -20.2 & 6.9 & -23.5 & 6.8 \\
\hline Isachenko Island & $7717 \mathrm{~N}$ & $08940 \mathrm{E}$ & 5 & -27.5 & 7.0 & -30.8 & 6.7 \\
\hline Cape Celyuskin & $7743 \mathrm{~N}$ & $10417 \mathrm{E}$ & 13 & -27.6 & 6.5 & -30.8 & 6.3 \\
\hline
\end{tabular}




\section{APPENDIX B. DETAILED TEMPERATURE DATA (NCDC 1996)}

\begin{tabular}{|c|c|c|c|c|c|}
\hline & \multirow{2}{*}{$\begin{array}{c}\text { Mean } \\
\text { temperature }\end{array}$} & \multicolumn{2}{|c|}{ Maximum temperature } & \multicolumn{2}{|c|}{ Minimum temperature } \\
\hline & & Average & Extreme & Average & Extreme \\
\hline \multicolumn{6}{|l|}{ DAY } \\
\hline 1 & -40.9 & -37.9 & -13.3 & -43.9 & -55 \\
\hline 2 & -40.7 & -36.6 & -12.2 & -44.8 & -55 \\
\hline 3 & -42.2 & -38.8 & -20 & -45.6 & -55.6 \\
\hline 4 & -43.4 & -41 & -27.8 & -45.8 & -55 \\
\hline 5 & -43.7 & -40.8 & -30.6 & -46.7 & -57.2 \\
\hline 6 & -44.2 & -41.7 & -28.9 & -46.7 & -57.8 \\
\hline 7 & -42.4 & -39.4 & -16.1 & -45.5 & -58.3 \\
\hline 8 & -43.8 & -40.7 & -18.9 & -46.9 & -56.1 \\
\hline 9 & -44.7 & -41.2 & -27.8 & -48.1 & -56.7 \\
\hline 10 & -42.9 & -40.3 & -27.8 & -45.5 & -57.2 \\
\hline 11 & -41.3 & -38.9 & -23.9 & -43.7 & -53.3 \\
\hline 12 & -41.3 & -38.6 & -23.9 & -44.1 & -52.8 \\
\hline 13 & -42 & -39.9 & -21.1 & -44.2 & -52.2 \\
\hline 14 & -40.6 & -37.5 & -18.9 & -43.7 & -53.9 \\
\hline 15 & -41.1 & -37.9 & -22.2 & -44.4 & -55 \\
\hline 16 & -41.4 & -38.1 & -28.9 & -44.7 & -56.7 \\
\hline 17 & -41.5 & -38 & -23.9 & -45 & -54.4 \\
\hline 18 & -41.8 & -38.7 & -22.2 & -44.9 & -53.9 \\
\hline 19 & -41.3 & -38 & -23.9 & -44.6 & -55 \\
\hline 20 & -42.5 & -39.5 & -23.9 & -45.4 & -55 \\
\hline 21 & -41.7 & -38.8 & -23.9 & -44.6 & -56.1 \\
\hline 22 & -41.5 & -38.5 & -27.8 & -44.4 & -53.3 \\
\hline 23 & -42.6 & -39.4 & -26.7 & -45.8 & -53.9 \\
\hline 24 & -41.4 & -38.1 & -20 & -44.7 & -53.9 \\
\hline 25 & -41.7 & -38.5 & -21.1 & -44.9 & -53.9 \\
\hline 26 & -42.6 & -39.2 & -26.7 & -46.1 & -53.9 \\
\hline 27 & -43.8 & -40.4 & -20 & -47.3 & -56.1 \\
\hline 28 & -43.9 & -40.1 & -22.2 & -47.6 & -56.1 \\
\hline 29 & -42.2 & -38.7 & -18.9 & -45.6 & -53.9 \\
\hline 30 & -42.2 & -39.1 & -24.4 & -45.4 & -55 \\
\hline 31 & -41.5 & -38.1 & -28.3 & -44.9 & -52.8 \\
\hline MONTH & -42.2 & -39.1 & -12.2 & -45.3 & -58.3 \\
\hline
\end{tabular}




\begin{tabular}{|c|c|c|c|c|c|}
\hline & \multirow{2}{*}{$\begin{array}{c}\text { Mean } \\
\text { temperature }\end{array}$} & \multicolumn{2}{|c|}{ Maximum temperature } & \multicolumn{2}{|c|}{ Minimum temperature } \\
\hline & & Average & Extreme & Average & Extreme \\
\hline \multicolumn{6}{|c|}{ Day } \\
\hline 1 & -19.1 & -15.7 & -1.1 & -22.4 & -42.2 \\
\hline 2 & -19.5 & -15.4 & -1.1 & -23.7 & -40 \\
\hline 3 & -19.2 & -16 & 1.1 & -22.3 & -37.2 \\
\hline 4 & -21.2 & -18 & 0 & -24.4 & -42.2 \\
\hline 5 & -18.9 & -15.2 & -1.1 & -22.5 & -40 \\
\hline 6 & -17.8 & -14.9 & 0 & -20.7 & -42.2 \\
\hline 7 & -17.8 & -14.7 & 1.7 & -20.9 & -38.9 \\
\hline 8 & -20.2 & -16.7 & -1.1 & -23.6 & -39.4 \\
\hline 9 & -20.5 & -17.5 & -5 & -23.5 & -44.4 \\
\hline 10 & -18.9 & -15.9 & -2.2 & -21.9 & -40.6 \\
\hline 11 & -20.9 & -17.1 & -2.2 & -24.7 & -40.6 \\
\hline 12 & -20.8 & -16.2 & -6.7 & -25.3 & -40 \\
\hline 13 & -19.6 & -16.3 & -2.8 & -22.8 & -45 \\
\hline 14 & -20.5 & -18.1 & -3.9 & -22.9 & -40 \\
\hline 15 & -21.2 & -16.8 & -6.1 & -25.5 & -41.1 \\
\hline 16 & -18.2 & -14.7 & 0 & -21.8 & -37.8 \\
\hline 17 & -17.3 & -14.6 & -0.6 & -20 & -42.8 \\
\hline 18 & -18.3 & -14.9 & 1.1 & -21.7 & -39.4 \\
\hline 19 & -19.7 & -15.8 & -1.1 & -23.6 & -35.6 \\
\hline 20 & -20.7 & -17.1 & -5 & -24.2 & -36.7 \\
\hline 21 & -20.6 & -17.8 & -3.9 & -23.4 & -36.1 \\
\hline 22 & -21 & -17.2 & -3.9 & -24.8 & -38.9 \\
\hline 23 & -23.3 & -20.3 & -10 & -26.2 & -42.8 \\
\hline 24 & -21.1 & -17.8 & -7.2 & -24.3 & -38.9 \\
\hline 25 & -21.9 & -18.6 & -10 & -25.2 & -41.1 \\
\hline 26 & -21.3 & -18.4 & 1.1 & -24.1 & -46.1 \\
\hline 27 & -20.1 & -16.9 & -5.6 & -23.4 & -43.9 \\
\hline 28 & -18.9 & -15.7 & -1.1 & -22.2 & -43.9 \\
\hline 29 & -17.6 & -14.5 & -0.6 & -20.7 & -45 \\
\hline 30 & -17.7 & -14 & -1.1 & -21.4 & -37.2 \\
\hline 31 & -20.4 & -17.7 & -2.2 & -23.2 & -37.2 \\
\hline
\end{tabular}




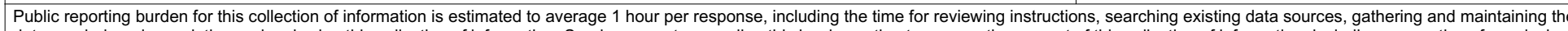

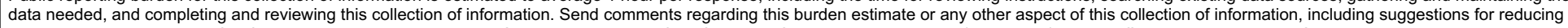

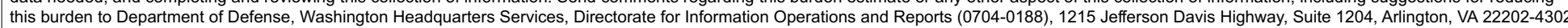

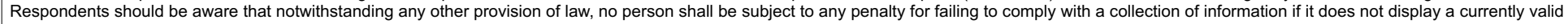
OMB control number. PLEASE DO NOT RETURN YOUR FORM TO THE ABOVE ADDRESS.
1. REPORT DATE (DD-MM-YY)
2. REPORT TYPE
April 2004
Technical Report
3. DATES COVERED (From - To)

4. TITLE AND SUBTITLE

Cold Regions Issues for Off-Road

Autonomous Vehicles

5a. CONTRACT NUMBER

5b. GRANT NUMBER

5c. PROGRAM ELEMENT NUMBER

\section{AUTHOR(S)}

5d. PROJECT NUMBER

Deborah Diemand and James H. Lever

5e. TASK NUMBER

5f. WORK UNIT NUMBER

7. PERFORMING ORGANIZATION NAME(S) AND ADDRESS(ES)

8. PERFORMING ORGANIZATION REPORT

U.S. Army Engineer Research and Development Center

Cold Regions Research and Engineering Laboratory

72 Lyme Road

Hanover, NH 03755-1290

ERDC/CRREL TR-04-6

9. SPONSORING/MONITORING AGENCY NAME(S) AND ADDRESS(ES)

10. SPONSOR / MONITOR'S ACRONYM(S)

11. SPONSOR / MONITOR'S REPORT NUMBER(S)

\section{DISTRIBUTION / AVAILABILITY STATEMENT}

Approved for public release; distribution is unlimited.

Available from NTIS, Springfield, Virginia 22161.

13. SUPPLEMENTARY NOTES

\section{ABSTRACT}

About half of Earth's land mass experiences mean temperatures below $0^{\circ} \mathrm{C}$ during the coldest month. Attendant conditions pose major challenges to the operation of off-road autonomous vehicles. Low-temperature effects on lubricants, materials, and batteries can impair a robot's ability to operate at all. Cold starting will be a serious problem if missions require long periods of engine shutdown. Deep snow can easily immobilize vehicles on terrain that would otherwise pose no problems. Blowing snow and icing can also degrade the performance of sensors needed for navigation and target detection. Winter operation of passenger vehicles and construction equipment provides guidance to surmount cold-regions effects on robotic vehicles. This report identifies problems likely to be encountered, simple preventative measures, and references for additional information. Conditions are sufficiently demanding that off-road autonomous vehicles must be designed for and tested in cold regions if they are expected to operate there successfully.

\begin{tabular}{|c|c|c|c|c|c|}
\hline 15. SUBJECT TERMS & $\begin{array}{l}\text { Batteries } \\
\text { Blowing snow } \\
\text { Ice }\end{array}$ & $\begin{array}{l}\text { Low temperature } \\
\text { Lubricants } \\
\text { Mobility }\end{array}$ & $\begin{array}{l}\text { Operation } \\
\text { Navigation } \\
\text { Robotic vehicles }\end{array}$ & \multicolumn{2}{|c|}{$\begin{array}{l}\text { Robots } \\
\text { Snow cover }\end{array}$} \\
\hline \multicolumn{3}{|c|}{ 16. SECURITY CLASSIFICATION OF: } & \multirow{3}{*}{$\begin{array}{l}\text { 17. LIMITATION OF } \\
\text { OF ABSTRACT }\end{array}$} & \multirow{3}{*}{$\begin{array}{l}\text { 18. NUMBER } \\
\text { OF PAGES }\end{array}$} & 19a. NAME OF RESPONSIBLE PERSON \\
\hline a. REPORT & b. ABSTRACT & c. THIS PAGE & & & 19b. TELEPHONE NUMBER (include area code) \\
\hline $\mathrm{U}$ & $\mathrm{U}$ & $\mathrm{U}$ & & & \\
\hline
\end{tabular}

